\title{
Coherent Optical Spectroscopy of Semiconductors
}

\author{
Hvam, Jørn Märcher; Langbein, Wolfgang Werner; Borri, Paola
}

Published in:

Proceedings of the European Quantum Electronics Conference

Publication date:

1998

Document Version

Publisher's PDF, also known as Version of record

Link back to DTU Orbit

Citation (APA):

Hvam, J. M., Langbein, W. W., \& Borri, P. (1998). Coherent Optical Spectroscopy of Semiconductors. In Proceedings of the European Quantum Electronics Conference (pp. 167-167). IEEE.

\section{General rights}

Copyright and moral rights for the publications made accessible in the public portal are retained by the authors and/or other copyright owners and it is a condition of accessing publications that users recognise and abide by the legal requirements associated with these rights.

- Users may download and print one copy of any publication from the public portal for the purpose of private study or research.

- You may not further distribute the material or use it for any profit-making activity or commercial gain

- You may freely distribute the URL identifying the publication in the public portal

If you believe that this document breaches copyright please contact us providing details, and we will remove access to the work immediately and investigate your claim. 
08.00-10.00 OThA - Time-Resolved Oplieal Interaction with Semiconductors

Presider: M. Aeschlimann, ETH, Zürich, SWITZERLAND

09.00 Tu15

\section{Femtosecond Photobiolog}

Villy Sundstromm

Department of Chemical Physics, Lund University, Box 124, S-221 00 Lund, Swede

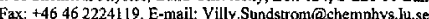

This tutorial will discuss techniques and applications of femtosecond photobiology. First, ultra-short pulse generation, detection and measurement techniques will be briefly reviewed. Then, several examples of ultrafast dyamics in biological system will be discussed. Ultrafast spectroscopy has provided a wealth of new information about the dynamics and function of many biological systems. As examples we will discuss the energy and electron transfer processes in photosynthetic and artificial light-energy converting systems and isomerization reactions of retinal chromophores in poroteins used by nature in energy converting and signaling systems.

Ultrashort pulses for dynamics in biology. Reactions forming the functional basi of hiological systems are elementary chemical reactions like energy and charge transfer, bond breaking and forming, isomerizations, proton transfers, etc. The direct study of these reactions in real time frequently requires sub- 100 femtosecond time resolution. Widely tunable and low-intensity pulses are often advantageous in order to facilitate the study of sensitive biological systems absorbing light over a broad range of wavelengths. How ultrashort-pulse Ti:Sapphire technology can be used to accomplish this will be discussed.

Photosynthetic energy comversion. Energy and electron transfer reactions are the basis of the photosynthetic light-energy converting processes. The availability of structural information to atomic resolution of many photosynthetic pigment-protein has made it possible to study in great detail the dynamics and function of these systems. Topics of current interest that will be discussed are: The nature of light excitations in photosynthetic antenna proteins; the mechanism of ature of light and transfer in antenna proteins and how electronic and nuclear coherence contribute to the funtion, the mechanion to the function, the mechanism of prinary charge separation in the photosynthetic photosynthesis and photonic systems.

photosynthesis and photonic systems.
A light-driven cis-trans isomerization reaction is extensively used by nature in A light-driven cis-trans isomerization reaction is extensively used by nature in
several pigment-proteins for light-energy conversion (bacteriorhodopsin, photoactive yellow protein) and signaling (rhodopsin and phytochrome). The nature of the primary photoreaction and how it is related to the function of the proteins will be
examined and compared with a model dye system.

Tel. $+45-4525$ 5758, Fax. $+45-45887762$, e-mail hvamômic.dtu.dk of the non-linear signal, such as phase-space filling. local-field effects and excitation-induced the dimensionality of the confined structure and/or the degree of localization by random

\subsection{OThA1 (Invited)}

Coherent Optical Spectroscopy of Semiconductors

M. Hvam. W. Langbein and P. Borri

Mikroelektronik Centret, The Techuical University of Denmark, DTU building 345 east.

DK-2800 Lyngby. Denmark.

Coherent oplical spectroscopy in the form of transien four-wave mixing (TFWM) has been used extensively to investigate the exciton and biexciton dynamics in semiconduclo

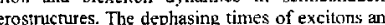
biexcitons is determined from the decay of the spectrally resolved non-linear signal as function of the delay (positive and negative) between the incident pulses in a two-bean TFWM experiment

From the temperature dependence of the dephasing times the exciton-phonon is determined. and the exciton-exciton interactions (collisions) are revealed by the exciton density dependence the dephasing times. The polarization selection rules of the TFWM signal are used to identify the biexciton contribution to the signal, as well as to identify the other origins dephasing.

Randomly fluctuating potentials, due to either alloy disorder or interface roughness in lowdimensional structures, tend to localize excitons and biexcitons and give rise to an inhomogeneous broadening of the excitonic resonances. At the same time the TFWM signal changes from a free-polarization-decay in the homogeneously broadened system to a photon echo in the inhomogeneously broadened system.

The localization alters the exciton-exciton and the exciton-plionon interactions and thercby changes the dephasing rates of the excitations. Further, the localization changes the exciton and biexciton binding energies, and in particular their ratio. Biexciton hinding energies are determined from spectral resolution of the nonlinear signal, as well as by nonlinear quanlumbeat spectroscopy. The latter is useful. or necessary, when the broadening is comparable w the biexciton binding energy.

The ratio between the binding energies of the biexciton and the exciton depends strongly on fluctuations. It changes from about 0.1 in homogeneous bulk semiconductors (Haynes' rule over about 02 in guasi two-dimensional quantum wells ${ }^{2}$ to about 0.4 in strongly localizediconfined zero-dimensional structures (quantum dots). Again, the crucial parameter is the localization energy (braadening) compared to the biexciton binding energy. In strongly iname an inhomogeneous distribution of biexciton hinding energies, which again results in the inhomogen as dest decay of the biexciton signal as a function of the delay between the incident pulses. This has falsely been interpreted as a fast (homogencous) dephasing of the inciden pulse ins bistribution of biexciton binding energies.

${ }^{1}$ J. Erland, K.-H. Pantke, V. Mizeikis, V.G. Lyssenko, and I.M. Hvam, Phys, Rev. B 50 $15047(1994)$

D. Birkedal, J. Singh, V.G. Lyssenko, J. Erland, and J.M. Hvam, Phys. Rev, Lett. 76, 672

(1996).

W. Langbein, J.M. Hvam, M. Umlauff, H. Kalt, B. Jobst, and D. Hommel, Phys. Rev. B 55, R7383 (1997). 